\title{
Current Status of the Policies and Laws of China's Low-carbon Development and its Institutional Approaches for Carbon Peaking and Carbon Neutrality Goals
}

\author{
Boyu Zhu*, Yuhan Wang, Hongyi Gao \\ Law School, Shandong University of Technology, Zibo, Shandong, China \\ *Corresponding Author
}

\begin{abstract}
China has formulated relevant policies and legislation to promote low-carbon development. The policies mainly include macro policies to promote low-carbon development, energy-saving policies, renewable energy policies and carbon sink policies, and the legislation mainly includes macro legislation to nudge low-carbon development and legislation on the reduction of carbon emissions and carbon absorption. Many problems still exist in the policies and legislation concerning China's low-carbon development, which makes it far from enough to support long-term and effective advancement of low-carbon development. The proposal of China's Carbon Peaking and Carbon Neutrality Goals urgently requires the renewal of relevant legislation and policies and the active creation of relevant systems for the legislation of low-carbon development policies. The systems mainly consist of planning system, standard system, licensing system, low-carbon industry catalog and exit system, carbon assessment and target responsibility system for the reduction of carbon emissions.
\end{abstract}

Keywords: Carbon Peaking and Carbon Neutrality, Policies of low-carbon development, Legislation of low-carbon development.

\section{Introduction}

In December 2015, China's President Xi responded to the Paris Agreement initiative at the United Nations Climate Conference in Paris, putting forward for the first time the goal of China's independent contribution to achieve carbon peaking by 2030. At the 75th UN General Assembly in 2020, President Xi made a solemn promise to the world on behalf of China to strive to achieve carbon peaking by 2030 and make efforts to attain carbon neutrality by 2060 . The significant and strategic Carbon Peaking and Carbon Neutrality goals are playing a leading and systematic role in low-carbon advancement of China. Low-carbon development is a comprehensive and systematic project that China has made endeavors to boost in many aspects, among which policies and legislation have played a profound role. Under the background of Carbon Peaking and Carbon Neutrality goals, it is indispensable to comprehensively review China's current policies and legislation related to low-carbon development and reasonably learn from those in western developed countries in nudging low-carbon advancement, and clarify the approach to institution to promote low-carbon development.

\section{The Status Quo of China's Low-carbon Development Policy}

China's measures to promote low-carbon development, like other countries in the world, both adopt policy measures more before enacting relevant laws[1]. These policies mainly include macroscopic policies to promote low-carbon development, energy-saving policies and renewable energy policies, also carbon sink policies.

\subsection{China's Macro Policy for Low-carbon Development \\ China signed the Framework Convention on Climate Change}

in 1992. In the following year, China became the first country in the world to formulate its own Agenda 21 based on the Global Agenda 21 Action Plan. This laid the foundation for China to formulate macro policies for low-carbon development.

In 2012, the 18th National Congress of the Communist Party of China comprehensively elaborated on the concept of ecological civilization, and at the same time elaborated China's basic environmental protection policies, putting forward the ideas of "insisting on giving priority to conservation, protection and natural restoration", and "promoting Green Economy, Circular Development, Low-carbon Development". The "priority principle" established by the 18th National Congress of the Communist Party of China embodied the most advanced concept of environmental protection policy. Prior to this, the core of the environmental protection policy established by China was the "coordination principle" rather than the "priority principle"[2] The shift in China's environmental protection policy has opened up a new path for low-carbon development policies and legislation. The report of the 19th National Congress of the Communist Party of China in 2017 proposed "accelerating the establishment of the legislation system and policy guidance for green production and consumption, and establish a sound economic system which is aimed at green and low-carbon circular development." The 14th Five-Year Plan issued in 2021 proposes "implementing the NDC targets for addressing climate change in 2030", and "formulating an specific plan for the carbon emission peak by 2030", "promoting clean and low-carbon energy with safety and efficiency", and "enhancing the Carbon Sink Capacity of ecology", anchoring efforts to achieve carbon neutrality by 2060, and "adopting more powerful policies and measures".

2.2 China's Energy-saving Policies and Renewable Energy Policies for Low-carbon Development 
In the field of energy conservation, in 2015, the General Administration of Quality Supervision, Inspection and Quarantine of China and the National Development and Reform Commission announced the Certification and Management Measures of Energy-saving and Low-Carbon Products to improve the energy efficiency of energy-using products and other products, control greenhouse gas emissions, and regulate and manage certification activities of low-carbon products. In addition, since April 2005, the Ministry of Finance and the National Development and Reform Commission have successively issued notices on adjusting the government procurement list of energy-saving products to continue to promote and standardize government procurement of energy-saving products.

In the field of renewable energy, in 2005, the National Development and Reform Commission of China compiled the Renewable Energy Industry Development Guidance Catalog to provide guidance for relevant departments to formulate supporting policies and measures, and conducted relevant research institutions and enterprises to exert technological research and development, project demonstration and investment and construction to provide guidance to promote the development of the renewable energy industry. In 2006, the National Development and Reform Commission formulated the Trial Measures for the Management of Renewable Energy Power Generation Prices and Cost Allocation, and in the same year it promulgated the Regulations on the Management of Renewable Energy Power Generation. In 2016, the National Development and Reform Commission issued the 13th Five-Year Plan for Renewable Energy Development on the basis of the 13th Five-Year Plan for Energy Development, which planned in more detail for the development of hydropower, wind power, solar energy, biomass energy, thermal energy and ocean energy. The Fourteenth Five-Year Plan for Renewable Energy Development released in 2021 sets more active development goals to promote the large-scale and high-proportion development and utilization of renewable energy.

\subsection{China's Carbon Sink Policy for Low-carbon Development}

The so-called "Carbon Sink" generally refers to offsetting its own carbon dioxide and other greenhouse gas emissions through means such as tree planting and afforestation, energy conservation and emission reduction[3]. The largest terrestrial ecosystem "forest" in the human living environment is a component of carbon cycle in the globe. It can play a very essential role in balancing carbon dioxide in the atmosphere by absorbing and storing carbon dioxide and other greenhouse gases.

China has issued regulations in the field of carbon sequestration to encourage the development and promotion of carbon sequestration projects under the clean mechanism. In December 2006 and August 2008, the State Forestry Administration respectively issued the Notice on Several Guiding Opinions on Carrying out Forestry Carbon Sink Work and the Notice on Strengthening Forestry's Response to Climate Change and Carbon Sink Management Work, so that the Afforestation activities and the responsibility of local governments for carbon sinks were regulated, which provides policy guarantees for local governments to carry out carbon sinks. In 2009, the No. 1 Document of the Central Committee of the Communist Party of China stated the idea of "building modern forestry, developing mountain forest products, eco-tourism and carbon sink forestry", which took the construction of carbon sink forestry as an important content of modern forestry to a new height, in Guiding Opinions on Promoting Forestry Carbon Sinks Trading.

\section{The Status Quo of China's Low-carbon Development Legislation}

China signed the Framework Convention on Climate Change in 1992, the Kyoto Protocol around the implementation of it in 1998, and the Paris Agreement in 2016. These international treaties are crucial parts of China's low-carbon legal system. China's domestic legislation to promote low-carbon development mainly includes macro-legislation to promote low-carbon development, as well as legislation on carbon emission reduction and carbon absorption.

\subsection{China's Relevant Macro-legislation to Promote Low-carbon Development}

China currently does not have a special low-carbon promotion law. In terms of legislation to promote low-carbon development, the relevant special legal document is the Resolution on Actively Addressing Climate Change in 2009. The resolution issued by the Standing Committee of the National People's Congress emphasizes the need to strengthen the construction of law in response to climate change, raise the awareness and capabilities of the entire society, and actively participate in international cooperation, regarding the low-carbon development law including this resolution as an important part of the formation and improvement of the socialist legal system with Chinese characteristics. Although this resolution involves low-carbon development, it has mainly symbolic meaning and does not have the legal effect of litigation.

In addition, what has an important link with low-carbon development is the environmental protection law. The Environmental Protection Law of the People's Republic of China revised in 2014 updated the concept of environmental protection.

The sixth article of it stipulated that "Citizens should adopt a low-carbon and frugal lifestyle". This was the first time that the term "low-carbon" has been used in relevant environmental legal documents. There has not been no definition of related concepts of "carbon" in the law, and there has not been clear regulation on low-carbon development.

\subsection{China's Legislation on Carbon Emission Reduction and Carbon Absorption}

Currently, China has no special laws on carbon emission reduction and carbon absorption. The relevant regulations are scattered in environmental protection and ecological legislation and energy resources legislation[4]. This is the basic legal environment for China's low-carbon development.

3.2.1 China's legislation on carbon emission reduction 
The issue of carbon emission reduction is mainly an energy issue. When it comes to China's legislation related with carbon emission reduction, what exists is mainly the legislation concerning energy conservation, energy efficiency improvement, renewable energy development, as well as the clean production promotion law and the circular economy promotion law.

Firstly, Energy Conservation Law and other laws and regulations. China promulgated the Energy Conservation Law in 1997 and revised it in 2007 and 2016. The legislative purpose of the Energy Conservation Law is to promote the idea transformation of the whole society, especially the major energy-consuming enterprises, to save energy, improve energy efficiency, and encourage the rational use of energy and the upgrading of energy technology. In addition, the Regulations on Energy Conservation in Public Institutions and the Regulations on Energy Conservation in Civil Buildings respectively regulate the energy conservation activities of public institutions and low-carbon buildings. First, under the basic framework of the Energy Conservation Law, various provincial governments have issued energy conservation regulations, which provide a legal basis for governments at all levels to implement energy conservation measures, especially some binding measures[5]. These energy-saving laws and regulations have promoted the reduction of carbon emissions in the whole society and low-carbon development.

Secondly, the Renewable Energy Law and other laws and regulations. China promulgated the Renewable Energy Law in 2005, and revised it in 2009 like the renewable energy development planning system, the mandatory grid-connected power generation system and the full guaranteed purchase system, as well as the government subsidy and tax incentive system for power generation projects. What is more, relevant ministries and commissions have successively promulgated a number of relevant regulations, and many localities have also issued local regulations on renewable energy in rural areas, promoting the development and utilization of renewable energy.

Thirdly, the Cleaner Production Promotion Law and the Circular Economy Promotion Law. China promulgated the Cleaner Production Promotion Law in 2002 (revised in 2012), and passed the Circular Economy Promotion Law in 2008. The promulgation and implementation of the Cleaner Production Promotion Law and the Circular Economy Promotion Law have played a prominent role in promoting low-carbon development in terms of energy conservation and emission reduction, improvement of resource and energy utilization efficiency, and vigorously developing new and renewable energy sources.

Additionally, laws such as the Coal Law revised in 2016 and the Electricity Law revised in 2015 also provided basic guarantees for promoting carbon emission reduction.

\subsubsection{Legislation on China's carbon absorption}

Carbon absorption mainly depends on the function of the "carbon sink" in ecosystem. Forest is the largest carbon storage and the most economical carbon absorber on the land.
As the main body of the terrestrial ecosystem, it has a unique carbon sink function. The Forest Law promulgated in 1984 (revised in 1998 and 2009) established afforestation, limited logging, and the establishment of a forest ecological benefit compensation fund, which played an effective role in the "increasing foreign exchange" of forests. In addition, China promulgated the Grassland Law in 2003 and revised it several times during the period. It stipulated many ecological construction measures in terms of grassland, which improved the grassland's ability to increase foreign exchange.

\section{China's Low-carbon Development Policy and Legal Institutional Approach}

There are still many problems in China's low-carbon development-related policies and legislation, which are far from enough to support long-term and effective low-carbon development. Since China has not achieved ecologicalization in the concept of policy and legislation, the current policy and legal system does not fully reflect the advanced nature of ecological culture, and environmental protection policies and laws have greater resistance to ecologicalization[6]. What are mentioned above is difficult to make current policy and legal system integrate with low-carbon development organically. The proposal of China's Carbon Peaking and Carbon Neutrality goals urgently require relevant legal and policy updates, and actively establishes relevant systems for low-carbon development policies and legislation. These systems mainly include planning systems, standard systems, licensing systems, low-carbon industry catalogs and exit systems, as well as Carbon assessment and carbon emission reduction target responsibility system.

\subsection{Planning System}

The low-carbon development planning system is an important carrier for combining low-carbon development goals with policies, laws and regulations, and is also the basic basis for guiding, supporting and regulating low-carbon development. To promote low-carbon development in an orderly manner, it is indispensable to scientifically formulate strategic goals for low-carbon development. Both the central and local governments, besides the low-carbon development plan involved in the five-year plan for national economic and social development, there should also be a special low-carbon development plan to adapt to the new situation in the field of low-carbon development. Through planning, we can create low-carbon cities and low-carbon communities, optimize the low-carbon spatial layout system, and guide the formation of low-carbon lifestyles and low-carbon consumption patterns. We can also create low-carbon demonstration parks and low-carbon enterprises, and give the leading role to industrial cluster and economic function zone to achieve the conversion into new growth drivers and promote industrial transformation and upgrading.

\subsection{Standard System}

The standards related to greenhouse gas emission control mainly include "atmospheric environmental quality standards, greenhouse gas emission standards, greenhouse gas detection method standards, and energy efficiency standards."[7] As the issue of global warming involves not only the use of 
atmospheric environmental capacity but also the activities of energy use, this issue makes the standards related to greenhouse gas emission and control integrate with environmental standards and energy efficiency standards. Therefore, the standard system in the field of low-carbon development refers to "the whole body of legal norms and documents in terms of stipulating of environment standards and the formulation, modification, classification, classification, standard limit, legal effect, legal significance, application and supervision of relevant energy efficiency standards"[8]. The establishment of a standard system is not only conducive to concretizing abstract scientific and technological norms, and enhancing the clarity and feasibility of policy and legislation from the technical level of policy and legislation, but also to the predictability and guidance for the subjects of greenhouse gas emission to promote the implementation of relevant standards.

\subsection{Licensing System}

Greenhouse gas emission permits refer to the act of entities engaged in statutory greenhouse gas emission activities in accordance with the provisions of policies and laws, that, after the review and approval of their application to the competent administrative department, with the competent administrative departments' permission, can engage in specific greenhouse gas emissions in the form of an activity behavior. From the perspective of extraterritorial experience, the British Greenhouse Gas Emissions Trading Regulations 2003 once stipulated that any entity engaged in other statutory greenhouse emissions activities must apply for an emission permit to the competent authority and conduct it within the scope of the permit[9]. From this point of view, China should also create this "command-and-control" permit system, so as to raise the threshold for greenhouse gas emitters to engage in corresponding emission activities, regulate their emission behavior, and control greenhouse gas emissions from the source.

\subsection{Low-carbon Industry Catalog and Exit System}

In the context of carbon neutrality, if low-carbon and zero-carbon technologies are not actively adopted for transformation, high-carbon industries and enterprises will face a survival crisis. Therefore, it is possible to set up low-carbon start-up funds, levy carbon taxes, financial subsidies, administrative penalties, etc., fully demonstrating the state's emphasis on and management of low-carbon industries. Under the overall national industrial policy framework, it is necessary to gradually establish a "white list", "grey list" and "black list" for entry into the national low-carbon industry market. The low-carbon industry catalogue should be as clear as the government procurement list of energy-saving products and highly operable, and the catalogue should be adjusted in due course. The content of the "white list" in the preparation of the low-carbon catalog should be classified and detailed, and it is strictly forbidden to establish projects that do not conform to the national low-carbon industry catalog. As for the established high-carbon projects that are not on the "white list", they should be treated differently. If they are projects that may achieve low-carbon transformation, they can be listed on the "grey list" for the implementation of a gradual transformation plan to encourage high-carbon enterprises to upgrade production technology, changing production thinking to achieve low-carbon transformation. If it is a project that is completely impossible to achieve low-carbon transformation and has extremely low production efficiency, it will be included in the "blacklist". Therefore, the high-energyconsuming backward technology and production capacity will be gradually eliminated through the development of carbon emission standards. Step-by-step withdrawal of items listed in the "blacklist".

\subsection{Carbon Assessment and Carbon Emission Reduction Target Responsibility System}

To promote low-carbon development policies and laws, in addition to environmental impact assessment and the "three simultaneous" system in environmental policy legislation, a carbon assessment system should also be gradually established. In addition to confirming the carbon assessment system in basic policies and laws, each industry should also have their own regulations. For example, the transportation industry and construction industry, which are large carbon emitters, should also have their own carbon assessment system and indicator system. What is more, there also exists carbon assessment in deforestation and degradation mechanisms, carbon assessment of grassland ecosystems, etc. In the project approval stage, the principle of prevention is supposed to be strictly implemented, and the carbon emission risk in the environmental impact assessment shall be evaluated.

Governments at all levels should implement a target responsibility system of carbon emission reduction. The leading force in the promotion of low-carbon development lies in the government. Therefore, the target responsibility system of the reduction of carbon emission should be incorporated into the evaluation system of the performance of leading cadres to strengthen their carbon emission reduction responsibilities.

\section{Conclusion}

Under the "Dual Carbon" goals, China should promote low-carbon development by comprehensively analyzing the status quo and problems of relevant policies and laws, and actively innovating relevant policies and legal systems. Policy and legislation of Low-carbon development is an emerging field, which is being explored at home and abroad. Low-carbon development policies and laws are still evolving, and some related issues have not yet reached a consensus. With the passage of time and the deepening of practice, related policies and legal systems will face further challenges.

\section{Acknowledgement}

This paper is funded by: Research topic of Prosecutorial Application Theory of The 2021 Supreme People's Procuratorate in 2021 "specting the Proof Standards and Burden of Proof of Environmental Civil Public Interest Litigation"; Shandong Province Social Science Planning Research Project "Research on the Rule of Law for Low-Carbon Development from the Perspective of Ecological Legal Philosophy" (Item Number: 19CFXJ10); Key R\&D 
Program of Zibo (School City Integration Development Category) Project "An Empirical Study on the Public Interest Litigation Mechanism of Restoration on Ecological Environment Damage in Zibo City" (Item Number: 2019ZBXC280).

\section{References}

[1] Boyu Zhu. Research on low-carbon development legislation[M]. People's Publishing House, 2020.

[2] Wei Hu. Carbon emissions trading system from the perspective of legal philosophy[M]. People's Publishing House, 2013.

[3] Youhai Sun. How to deal with the relationship between achieving "Dual Carbon" goals and climate change legislation[N]. China Environment News, July 22, 2021.

[4] Yanfang Li, Yicheng Wu. China's low-carbon economy law and policy framework: Current status, deficiencies and improvements[J]. Journal of China University of Geosciences, 2011, 6: 8.

[5] Ye Qi. China low-carbon development report (2013)Policy implementation and institutional innovation[M] Social Sciences Archives, 2013.

[6] Cai Shouqiu. Jurisprudence based on ecological civilization[M]. China Publishing House, 2014.

[7] Liu Mingming. Research on the legal system of greenhouse gas emission control[M]. Law Press, 2012.

[8] Zhaoxia Yang. On the legal status of environmental standards-Reflections and supplements to mainstream views[J]. Administration and Law, 2008, 1: 110.

[9] Mingming Liu. Research on the legal system of greenhouse gas emission control[M]. Law Press, 2012.

[10] Shuang He. A Comparative study of low-carbon industry legislation in China and the United States[J]. Industry and Technology Forum, 2019, 21: 33. 